(c) American Dairy Science Association, 2006.

\title{
Augmentation of Vaccenate Production and Suppression of Vaccenate Biohydrogenation in Cultures of Mixed Ruminal Microbes
}

\author{
S. Fukuda, Y. Suzuki, M. Murai, N. Asanuma, and T. Hino ${ }^{1}$ \\ Department of Life Science, Meiji University, Tama-ku, Kawasaki 214-8571, Japan
}

\begin{abstract}
To increase ruminal outflow of trans-vaccenic acid $(t$ VA), a new strain of Butyrivibrio fibrisolvens (MDT-10) was isolated that has a great ability to hydrogenate linoleic acid (LA) to $t$-VA. When strain MDT-10 was added to the batch cultures of mixed ruminal microbes ( $1 \%$ of the total number of viable ruminal bacteria), LA conversion to $t$-VA increased greatly; after $3 \mathrm{~h}, t$-VA levels were $>4$-fold higher than the control. By $10 \mathrm{~h}$, all of the $t$-VA was hydrogenated to stearic acid. However, when a new strain of Bifidobacterium adolescentis (HF11 ), which has a high capacity for incorporation of $t$ VA, was added in conjunction with MDT-10 (1\% of the total number of ruminal bacteria), $t$-VA levels after 10 $\mathrm{h}$ were 6 times higher than with MDT-10 alone. These results suggest that $t$-VA produced by MDT-10 was incorporated into HF-11 cells, resulting in protection of $t$-VA from $t$-VA-hydrogenating microbes. Similar results were obtained in a continuous culture of mixed ruminal microbes in which addition of HF-11 simultaneously with MDT-10 increased the amount of $t$-VA in the effluent 2.5-fold. Both MDT-10 and HF-11 appeared to grow readily in the presence of mixed ruminal microbes. Sixty-two percent of $t$-VA incorporated by HF11 was present in the free form, whereas 19,15 , and $3 \%$, respectively, were incorporated into monoacylglycerol, glycerophospholipid, and diacylglycerol fractions. Because these lipids can be digested in the small intestine, it is likely that most $t$-VA in HF-11 cells is absorbed. Thus, introduction of MDT-10 and HF-11 simultaneously to the rumen might increase the amount of $t$-VA absorbed and might consequently increase the conversion of $t$-VA to conjugated linoleic acid in tissue.

Key words: conjugated linoleic acid, trans-vaccenic acid, Butyrivibrio fibrisolvens, Bifidobacterium adolescentis
\end{abstract}

\section{INTRODUCTION}

Conjugated linoleic acid (CLA), particularly cis 9, trans $11(c 9, t 11)$-CLA, has been reported to exhibit

Received August 3, 2005.

Accepted November 2, 2005.

${ }^{1}$ Corresponding author: hino@isc.meiji.ac.jp beneficial effects on health, including protection against carcinogenesis, atherosclerosis, and tumorigenesis and the improvement of hyperinsulinemia and immune functions (Pariza, 2004; Wahle et al., 2004). Furthermore, CLA, especially $t 10, c 12$-CLA, has reduced the ratio of body fat to muscle mass and has altered the ratio of low-density to high-density lipoprotein cholesterol (Pariza, 2004; Wang and Jones, 2004).

In contrast, it has been suggested that $t 10, c 12$-CLA has detrimental effects (Wahle et al., 2004), including procarcinogenic effects in animal models of colon and prostate cancer (Rajakangas et al., 2003). Thus, $c 9, t 11$ CLA appears to benefit health with less risk than $t 10$, $c 12$-CLA. In ruminants, $t 10, c 12$-CLA is a potent inhibitor of milk fat synthesis, whereas $c 9, t 11$-CLA has no such effect (Bauman and Griinari, 2003; Peterson et al., 2004).

Representative foods containing CLA include the meat and milk of ruminants, which primarily contain $c 9, t 11$-CLA. In ruminants, CLA is produced via 2 routes. One is microbial isomerization of linoleic acid (LA) to CLA in the rumen (Harfoot and Hazlewood, 1997). However, most of this CLA is hydrogenated to trans-vaccenic acid $(\boldsymbol{t}$-VA) and then to stearic acid (SA). Therefore, only a small amount of nonbiohydrogenated CLA can be absorbed from the small intestine. The other route of CLA production is $\Delta^{9}$-desaturation of $t$ VA, absorbed from the small intestine, to CLA in the tissues of the host animals (Griinari et al., 2000). Recent studies indicate that a high percentage of milk CLA (78 to $93 \%$ ) is derived from $\Delta^{9}$-desaturation of $t$-VA (Corl et al., 2001; Piperova et al., 2002), and meat CLA may also be produced from absorbed $t$-VA (Daniel et al., 2004). Thus, increasing $t$-VA production in the rumen may be a feasible method for increasing the CLA content of milk and meat. It has been reported that $t$-VA production in the rumen, as well as CLA content in milk and meat, was enhanced by feeding cows oils containing high levels of polyunsaturated fatty acids (PUFA), including soybean, corn, peanut, sunflower, linseed, and fish oils (Dhiman et al., 2000; Chouinard et al., 2001; Duckett et al., 2002). Because PUFA are known to have toxic effects on microbes (Harfoot and Hazlewood, 1997), this increase may be due to suppression of the 
growth or activity of some PUFA-hydrogenating microbes. The addition of ionophores, such as monensin (Fellner et al., 1997; Sauer et al., 1998), and copper (Morales et al., 2000) has also been reported to enhance the CLA content in milk, but these substances may be similarly toxic to PUFA-hydrogenating microbes. It has been suggested that decreasing $\mathrm{pH}$ increases postruminal flow of $t$-VA (Qiu et al., 2004), but low $\mathrm{pH}$ may also inhibit the growth of acid-sensitive microbes. Thus, great care is required for use of substances or treatments that suppress microbial growth, as they could depress overall ruminal metabolism, including fiber digestion (Hino and Asanuma, 2003).

Butyrivibrio fibrisolvens, a representative PUFA-hydrogenating ruminal bacterium, produces the highest levels of $t$-VA from LA among bacteria surveyed (Harfoot and Hazlewood, 1997; Jiang et al., 1998; Kim et al., 2000). Introduction of Butyr. fibrisolvens, especially strains that have a high capacity to convert LA to $t$-VA (Fukuda et al., 2005), into the rumen may increase $t$-VA production, and the prevention of $t$-VA hydrogenation to $\mathrm{SA}$ in the rumen may increase $t$-VA absorption. If $t$-VA is incorporated into microbial cells without hydrogenation, $t$-VA could be protected from $t$-VA-hydrogenating microbes (encapsulation of $t$-VA). However, the ability of ruminal microbes, including Butyr. fibrisolvens, to incorporate fatty acids (FA) is generally low (Hino et al., 1993a).

The principal objectives of this study were 1) to find Butyr. fibrisolvens strains with a high capacity to convert LA to $t$-VA, 2) to find gastrointestinal bacteria with a high capacity to incorporate $t$-VA, and 3) to examine whether the addition of a $t$-VA-producing strain and a $t$ VA-incorporating bacterium increases $t$-VA production and accumulation in cultures of mixed ruminal microbes.

\section{MATERIALS AND METHODS}

\section{Sources of Bacteria and Culture Conditions}

Butyrivibrio fibrisolvens TH1 was obtained as described previously (Fukuda et al., 2005). Strain MDT10 was newly isolated from the rumen of a Japanese native goat by Hungate's role-tube method and was identified according to Bryant (1986). Similarly, Bifidobacterium adolescentis HF-11 (Scardovi, 1986), Escherichia coli HF-23 (Orskov, 1986), Bifidobacterium breve HF-31 (Scardovi, 1986), and Lactobacillus fermentum HF-3 (Kandler and Weiss, 1986) were isolated from human feces and identified in this study.

Each bacterium was routinely grown in 30 - or $50-\mathrm{mL}$ serum vials containing 15 or $30 \mathrm{~mL}$ of growth medium consisting of clarified ruminal fluid (Miyazaki et al., 1992) and a basal medium (1:3) containing ( $\mathrm{g} / \mathrm{L}) 0.45$
$\mathrm{K}_{2} \mathrm{HPO}_{4}, 0.45 \mathrm{KH}_{2} \mathrm{PO}_{4}, 0.9\left(\mathrm{NH}_{4}\right)_{2} \mathrm{SO}_{4}, 0.9 \mathrm{NaCl}, 0.12$ $\mathrm{CaCl}_{2} \cdot 2 \mathrm{H}_{2} \mathrm{O}, 0.19 \mathrm{MgSO}_{4} \cdot 7 \mathrm{H}_{2} \mathrm{O}, 1.0$ trypticase-peptone (BBL, Becton Dickinson, Cockeysville, MD), 1.0 yeast extract (Difco Laboratories Inc., Detroit, MI), 3.0 glucose, and 0.6 cysteine $\cdot \mathrm{HCl}(\mathrm{pH} 7.0)$. Batch cultures were incubated in triplicate at $39^{\circ} \mathrm{C}$, maintaining the $\mathrm{pH}$ between 6.5 and 7.0 (Miyazaki et al., 1992).

Both LA and $t$-VA were added in a mixture with BSA at 1:3 (Fukuda et al., 2005). Cell growth was estimated by measuring the optical density at $600 \mathrm{~nm}\left(\mathbf{O D}_{\mathbf{6 0 0}}\right)$ or cellular nitrogen (cell-N) as reported previously (Fukuda et al., 2005). Viable cells of Butyr. fibrisolvens, Bifid. adolescentis, and mixed ruminal bacteria were enumerated by the roll-tube method (Fukuda et al., 2005).

\section{Isolation of Bacteria that Have a High Capacity to Incorporate $t-V A$, but Have No Capacity to Hydrogenate $t-V A$}

Bacteria were isolated from the rumen of goats and from human feces by the role-tube method just described, and each bacterium was grown overnight in a medium containing $t$-VA $(5 \mu \mathrm{mol} / 15 \mathrm{~mL})$. After removal of $t$-VA adsorbed on the bacterial cell surface by washing with $0.1 \%$ (vol/vol) Triton X-100, total lipids in cells were extracted with chloroform:methanol (2:1), and the amount of $t$-VA was determined by GLC as described subsequently.

The ability to hydrogenate $t$-VA was determined by measuring LA isomerase (LA-I) and CLA reductase (CLA-R) activities as described subsequently. The rate of $t$-VA uptake was measured as follows. Each bacterial strain was grown to an $\mathrm{OD}_{600}$ of 1.0 , and after the addition of $t$-VA ( $5 \mu \mathrm{mol} / 15 \mathrm{~mL}$ of culture), the culture was incubated until an $\mathrm{OD}_{600}$ of 1.5 was reached (late log stage). The rate of $t$-VA uptake was calculated for each culture $(\mu \mathrm{mol} / \mathrm{h})$ and then divided by the estimated cell$\mathrm{N}$ (i.e., cell-N determined by the average of cell-N at an $\mathrm{OD}_{600}$ of 1.0 and cell-N at an $\mathrm{OD}_{600}$ of 1.5) to generate the rate of $t$-VA uptake per cell-N ( $\mu \mathrm{mol} / \mathrm{h}$ per $\mathrm{mg}$ of cell-N).

\section{Culture Conditions of Mixed Ruminal Microbes}

Mixed ruminal microbes were obtained from ruminal fluid by squeezing ruminal contents from a Japanese native goat with cheesecloth (Hino et al., 1993b). Growth medium and conditions for batch culture of mixed ruminal microbes were basically as described previously.

Apparatus and general procedures for continuous culture were as described previously (Hino and Hamano, 1993; Hino et al., 1993a). Briefly, the apparatus con- 
sisted of 3 identical sets of equipment, including a reservoir bottle to supply saline solution, a peristaltic pump, an overflow-type fermenter $(300 \mathrm{~mL})$ in a water bath $\left(39^{\circ} \mathrm{C}\right)$, and a bottle to collect the effluent in an ice bath (samples for analysis). Prior to and during culture incubation, $\mathrm{CO}_{2}$ gas was purged through the entire system to avoid contact with $\mathrm{O}_{2}$.

Mixed ruminal microbes were obtained by diluting ruminal fluid with saline solution (1:2), and the microbial suspension was introduced into fermenters under a stream of $\mathrm{CO}_{2}$. Dilution rate was set at $0.1 / \mathrm{h}$, and the $\mathrm{pH}$ was maintained at 6.8 to 6.9 . A feed (3 g per fermenter) containing 50\% cornstarch, $15 \%$ cellulose powder (Advantech, Tokyo, Japan), 10\% fructo-oligosaccharide (Meiji Seika Kaisya, Tokyo, Japan), 20\% casein, and 5\% trypticase-peptone (BBL) was added to the fermenters every $6 \mathrm{~h}$. Mixed with the feed, LA also was added every $6 \mathrm{~h}(70 \mu \mathrm{mol}$ per fermenter $)$. At the initiation of continuous culture, Butyr. fibrisolvens MDT-10 and Bifid. adolescentis HF-11 were added to fermenters at a concentration of $1 \%\left(1 \times 10^{9} \mathrm{cfu} / \mathrm{mL}\right)$ of the total viable counts of mixed ruminal bacteria $(1 \times$ $10^{11} \mathrm{cfu} / \mathrm{mL}$ ). Effluents were collected every hour for analysis. Culture incubation was carried out for $24 \mathrm{~h}$ using one fermenter per test group, and the experiment was repeated 2 more times $(\mathrm{n}=3)$ following a $3 \times 3$ Latin square design.

\section{Identification of the Molecular Species of $t-V A$ Incorporated in a t-VA-Incorporating, Non-t-VA-Hydrogenating Bacterium (Bifid. adolescentis HF-11)}

Bifidobacterium adolescentis HF-11 cells grown with $t$-VA $(5 \mu \mathrm{mol} / 15 \mathrm{~mL}$ of culture) to late log stage $(5 \mathrm{~h})$ were washed with $0.1 \%$ Triton X-100, and total lipids were extracted as described previously. The lipids were separated by thin-layer chromatography (TLC; Silica Gel B-10, Wako Pure Chemicals, Osaka, Japan; $10 \times$ $20 \mathrm{~cm}$ ) using a developing solvent of chloroform:acetone (96:4). To separate 1- and 2-monoacylglycerol (MG) more clearly, chloroform:methanol (95:5) was also used. As standard substances, triolein (triacylglycerol), oleic acid (free FA), diolein [mixture of 1,3- and 1, 2-diacylglycerol (DG)], 1-monoolein, 2-monoolein, and phosphatidylcholine (phospholipids; PL), all purchased from Sigma (St. Louis, MO), were used. Subsequently, $t$-VA in each spot was quantified by GLC. Spots on TLC plates were detected by the conventional method (Fukuda et al., 2002), and PL was detected by spraying the Dittmer-Lester reagent (Dittmer and Lester, 1964).

Because $t$-VA was detected in the TLC spots corresponding to MG and DG, MG and DG were confirmed as follows. The bands on TLC plates corresponding to
MG and DG were scraped off the plates and extracted with chloroform:methanol (2:1). The extracts were divided into 2 equal parts; the first was for quantification of FA by GLC, and the other was for quantification of glycerol. Glycerol was quantified using a kit for the determination of blood triacylglycerol (Triglyceride ETest Wako; Wako Pure Chemicals). Briefly, MG and DG were hydrolyzed by lipoprotein lipase, and liberated glycerol was measured by the enzymatic method reported by Spayd et al. (1978).

\section{Quantification of FA and Organic Acids}

Lipids were extracted by shaking cultures or effluents in continuous culture with isopropanol:isooctane: $6 \mathrm{~N}$ $\mathrm{H}_{2} \mathrm{SO}_{4}$ (20:10:1) as reported previously (Fukuda et al., 2002). The lipids were then transmethylated with $5 \%$ $\mathrm{HCl}$ in methanol at $60^{\circ} \mathrm{C}$ for 20 min under a gas phase of $\mathrm{N}_{2}$ (Fukuda et al., 2002). The methylated FA were analyzed by GLC and mass spectrometry as described previously (Fukuda et al., 2002). Organic acids produced by isolated bacteria and in the continuous culture of mixed ruminal microbes were analyzed by HPLC to identify the bacteria and to estimate the alterations in fermentation, respectively (Fukuda et al., 2002).

\section{Assay of LA-I and CLA-R Activities}

To measure LA-I and CLA-R activities in intact cells, cultures grown to the late log stage were immediately cooled in an ice bath and centrifuged $(20,000 \times g, 10 \mathrm{~min}$, $\left.4^{\circ} \mathrm{C}\right)$. The pellets were washed twice with anaerobic 50 $\mathrm{m} M$ KPi buffer ( $\mathrm{pH}$ 7.0) and immediately subjected to enzyme assay (Fukuda et al., 2005). The LA-I and CLA$R$ activities were assayed by the method of Hunter et al. (1976) with some modifications as described previously (Fukuda et al., 2005).

Enzyme activity was expressed as specific activity (i.e., $\mu \mathrm{moles} / \mathrm{min}$ per $\mathrm{mg}$ of cell-N), which reflects the amount of enzyme per cell. Cellular nitrogen was determined by the Kjeldahl method followed by the quantitation of ammonia by the indophenol method (Fukuda et al., 2005).

\section{Statistical Analyses}

Differences among bacterial strains were analyzed by one-way ANOVA, and Tukey's test was used when the $F$-test was significant. In batch culture and continuous culture experiments, data were analyzed by 2 -way ANOVA (bacterial addition and incubation time). Tukey's test was done when the interaction was significant. Differences with $P$ values $<0.05$ were considered significant. Data are expressed as means \pm SE. All sta- 
Table 1. Capacity of isolated bacteria to incorporate trans-vaccenic acid ( $t$-VA) and specific activities of linoleic acid isomerase (LA-I) and conjugated linoleic acid reductase (CLA-R)

\begin{tabular}{llll}
\hline & $\begin{array}{l}t \text {-VA incorporated } \\
(\mu \mathrm{mol} / \mathrm{mg} \text { of cell-N })\end{array}$ & LA-I & CLA-R \\
\cline { 2 - 4 } Bacterium & $0.76 \pm 0.09^{\mathrm{a}}$ & $\mathrm{ND}^{3, \mathrm{~b}}$ & $\mathrm{ND}$ \\
Bifidobacterium adolescentis $\mathrm{HF}-11$ & $0.18 \pm 0.03^{\mathrm{b}}$ & $\mathrm{ND}^{\mathrm{b}}$ & $\mathrm{ND}$ \\
Escherichia coli HF-23 & $0.09 \pm 0.01^{\mathrm{c}}$ & $0.07 \pm 0.01^{\mathrm{a}}$ & $\mathrm{ND}$ \\
Bifidobacterium breve HF-31 & $0.07 \pm 0.01^{\mathrm{c}}$ & $\mathrm{ND}^{\mathrm{b}}$ & $\mathrm{ND}$ \\
Lactobacillus fermentum HF-3 & $\mathrm{ND}$ & $0.52 \pm 0.03$ & $0.29 \pm 0.02$ \\
Butyrivibrio fibrisolvens MDT-10 & &
\end{tabular}

${ }^{\mathrm{a}-\mathrm{c}}$ Means with different superscript letters within a column differ significantly $(P<0.01)$.

${ }^{1}$ Amount of $t$-VA in the cells grown to full growth ( 5 to $6 \mathrm{~h}$; mean $\pm \mathrm{SE} ; \mathrm{n}=3$ ); Cell-n $=$ cellular nitrogen.

${ }^{2}$ Activities are expressed as $\mu \mathrm{mol} / \mathrm{min}$ per $\mathrm{mg}$ of cell-N (mean $\pm \mathrm{SE} ; \mathrm{n}=3$ ).

${ }^{3} \mathrm{ND}=$ Not detected $(P<0.01)$

tistical analyses were performed with the SigmaStat Statistical Analysis System (Jandel Scientific, San Rafael, CA).

\section{RESULTS AND DISCUSSION}

\section{Isolation of a Butyr. fibrisolvens Strain with a High Capacity to Convert LA to t-VA and Bacteria with a High Capacity to Incorporate t-VA}

A newly isolated strain of Butyr. fibrisolvens (MDT10) converted LA to $t$-VA approximately $30 \%$ faster $(P$ $<0.05)$ than strain TH1, which had the highest capacity to produce $t$-VA reported so far (Fukuda et al., 2005; $1.6 \mathrm{vs} .1 .2 \mu \mathrm{mol} / \mathrm{h}$ per $\mathrm{mg}$ of cell-N). Activity of LA-I in MDT-10 was comparable with that in TH1 (0.53 vs. $0.45 \mu \mathrm{mol} / \mathrm{min}$ per $\mathrm{mg}$ of cell-N; $P>0.05$ ), whereas CLA$\mathrm{R}$ activity in MDT-10 was nearly $40 \%$ higher than in TH1 ( 0.26 vs. $0.19 \mu \mathrm{mol} / \mathrm{min}$ per $\mathrm{mg}$ of cell-N; $P<0.01$ ). This result is consistent with the fact that MDT-10 rapidly converted LA to $t$-VA with little accumulation of CLA when the initial cell numbers were $>1 \times 10^{10} \mathrm{cfu} /$ $\mathrm{mL}$ (data not shown). When the numbers were lower, CLA was accumulated once and then disappeared slowly. As explained previously (Fukuda et al., 2005), when cell numbers are low, more LA may be adsorbed to cells, and cell growth delays are possibly due to temporary cell damage. During this growth retardation, electron supply from fermentation may be decreased, which results in decreased electron donation to CLA-R.

Neither rumen nor stock ruminal bacteria, including Butyr. fibrisolvens, yielded bacteria that rapidly incorporated $t$-VA (data not shown). Even strain MDT-10, which efficiently converts LA to $t$-VA, incorporated only low levels of $t$-VA (Table 1). However, 4 bacteria that are able to incorporate $t$-VA were isolated from human feces. Of these, Bifid. adolescentis HF-11 demonstrated the highest concentration of incorporated $t$ - $\mathrm{VA}(P<0.01$; Table 1).
The total amount of $t$-VA in cultures (cells plus culture supernatant) recovered after incubation was nearly equivalent to the amount of $t$-VA initially added to the medium. Because HF-11 does not synthesize $t$ VA de novo (see subsequent), these results indicate that HF-11 cannot hydrogenate $t$-VA. In addition, HF-11 demonstrated no LA-I or CLA-R activity (Table 1).

Strain HF-11 incorporated oleic acid (c9-C18:1) as readily as $t$-VA, whereas the rate of $\mathrm{C} 18: 0$ (SA) uptake was one-third the rate of $t$-VA uptake $(P<0.05$; Table 2 ). This is important in that HF-11 carries $t$-VA more readily than SA. The rate of C18:2 (LA and CLA) uptake was one-tenth the rate of $t$-VA uptake, and C18:3 (linolenic acid) was incorporated more slowly than C18:2 $(P<0.05$; Table 2).

\section{Molecular Species of t-VA Incorporated in Bif. adolescentis HF-11}

When HF-11 was grown to saturation with $t$-VA (5 $\mu \mathrm{mol} / 30 \mathrm{~mL}$ of medium), $>90 \%$ of $t$-VA was recovered in the cells. The lipids in HF-11 contained mainly free FA, MG, DG, and PL (Figure 1). As shown in Table 3, $t$-VA was present in the free FA $(62 \%)$, DG $(1,2-\mathrm{DG}$

Table 2. Capacity of Bifidobacterium adolescentis HF-11 to incorporate several fatty acids (FA)

\begin{tabular}{ll}
\hline FA & $\begin{array}{l}\text { FA incorporated } \\
(\mu \text { mol/h per mg } \\
\left.\text { of cell- }{ }^{1}\right)\end{array}$ \\
\hline Stearic acid (C18:0) & $0.04 \pm 0.02^{\mathrm{b}}$ \\
Oleic acid (cis9-C18:1) & $0.13 \pm 0.03^{\mathrm{a}}$ \\
Vaccenic acid (trans11-C18:1) & $0.13 \pm 0.02^{\mathrm{a}}$ \\
Linoleic acid (cis9, cis12-C18:2) & $0.01 \pm 0.01^{\mathrm{c}}$ \\
Conjugated linoleic acid $($ cis9, trans11-C18:2) & $0.01 \pm 0.01^{\mathrm{c}}$ \\
Linolenic acid (cis9, cis12, cis15-C18:3) & $\mathrm{ND}^{2, \mathrm{~d}}$ \\
\hline${ }^{\mathrm{a}-\mathrm{d} \text { Means }( \pm \mathrm{SE}) \text { with different superscript letters within a column }}$ \\
differ significantly $(P<0.05 ; \mathrm{n}=3)$. & \\
${ }^{1}$ Cell-N $=$ Cellular nitrogen. & \\
${ }^{2} \mathrm{ND}=$ Not detected $(P<0.01)$. &
\end{tabular}




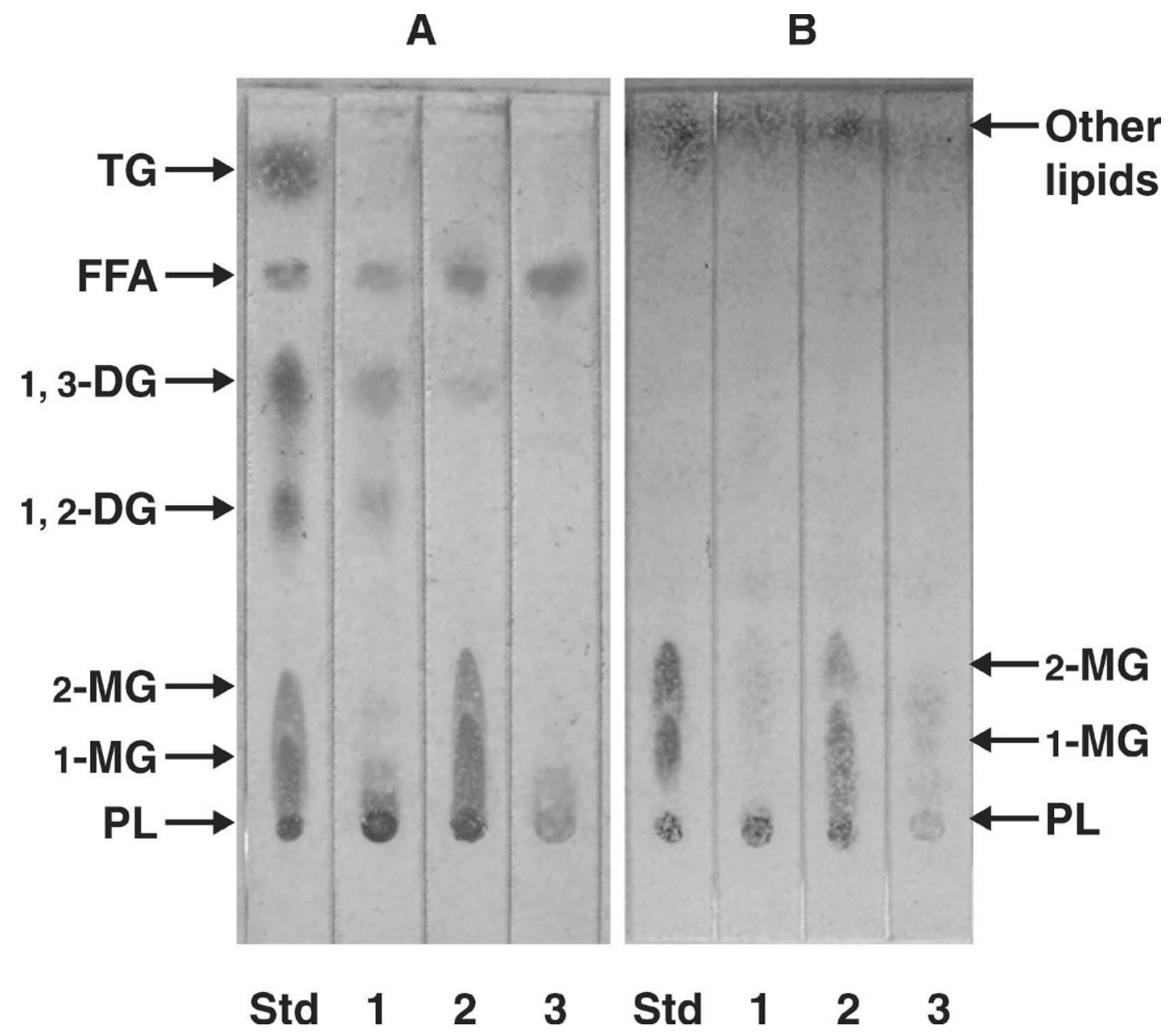

Figure 1. Thin-layer chromatograms of the lipids in Bifidobacterium adolescentis HF-11 grown in the presence (lane 2) or absence (lane 1) of trans-vaccenic acid ( $t$-VA). Lane 3: Lipids in the cells grown with $t$-VA that were hydrolyzed with weak alkali [A: chloroform:acetone (96:4); B: chloroform:methanol (95:5)]. TG = triacylglycerol; DG = diacylglycerol; MG = monoacylglycerol; PL= phospholipid; Std = standard substances.

Table 3. Fatty acid (FA) composition of lipids in Bifidobacterium adolescentis HF-11 grown in the presence or absence of trans-vaccenic acid $(t$-VA; $5 \mu \mathrm{mol} / 30 \mathrm{~mL}$ of medium)

\begin{tabular}{|c|c|c|c|c|c|c|c|c|c|c|}
\hline \multirow{2}{*}{$\begin{array}{l}\text { Molecular } \\
\text { species of } \\
\text { lipids }\end{array}$} & \multirow{2}{*}{$t$-VA $^{1}$} & \multicolumn{6}{|c|}{ Molar percentage of FA } & Total FA & \multicolumn{2}{|c|}{$t$-VA in cells } \\
\hline & & & & & & & & ( $\mu$ mol per vial) & ( $\mu$ mol per vial) & $(\%)$ \\
\hline $\mathrm{DG}^{2}$ & $\begin{array}{l}- \\
+\end{array}$ & $\begin{aligned} 17 & \pm 4^{*} \\
0 & \pm 0\end{aligned}$ & $\begin{aligned} 48 & \pm 5^{*} \\
8 & \pm 1\end{aligned}$ & $\begin{aligned} 35 & \pm 4^{*} \\
8 & \pm 1\end{aligned}$ & $\begin{array}{l}0 \pm 0 \\
0 \pm 0\end{array}$ & $\begin{aligned} 0 & \pm 0 \\
84 & \pm 3^{*}\end{aligned}$ & $\begin{array}{l}0 \pm 0 \\
0 \pm 0\end{array}$ & $\begin{array}{l}0.73 \pm 0.05^{*} \\
0.23 \pm 0.02\end{array}$ & 0.15 & 3 \\
\hline $\mathrm{PL}^{4}$ & $\begin{array}{l}- \\
+\end{array}$ & $\begin{aligned} 13 & \pm 3^{*} \\
0 & \pm 0\end{aligned}$ & $\begin{aligned} 58 & \pm 6^{*} \\
7 & \pm 1\end{aligned}$ & $\begin{array}{l}6 \pm 2 \\
2 \pm 1\end{array}$ & $\begin{array}{l}7 \pm 2^{*} \\
0 \pm 0\end{array}$ & $\begin{aligned} 0 & \pm 0 \\
78 & \pm 4^{*}\end{aligned}$ & $\begin{array}{l}16 \pm 4 \\
13 \pm 2\end{array}$ & $\begin{array}{l}1.90 \pm 0.13^{*} \\
0.88 \pm 0.07\end{array}$ & 0.69 & 15 \\
\hline
\end{tabular}

$1_{+}=$Added; - = not added.

${ }^{2} \mathrm{DG}=1$, 2-Diacylglycerol plus 1, 3-diacylglycerol.

${ }^{3} \mathrm{MG}=1$-Monoacylglycerol plus 2-monoacylglycerol.

${ }^{4} \mathrm{PL}=$ Phospholipid.

*Means with an asterisk in each block differ significantly $(P<0.01 ; \pm \mathrm{SE} ; \mathrm{n}=3)$. 
Table 4. Fatty acid (FA) composition of total lipids in Butyrivibrio fibrisolvens MDT-10 and Bifidobacterium adolescentis HF-11 cells grown in the presence of linoleic acid (LA) ${ }^{1}$

\begin{tabular}{|c|c|c|c|c|c|c|c|c|}
\hline \multirow[b]{2}{*}{ Bacterial strain } & \multicolumn{7}{|c|}{ Molar percentage } & \multirow[b]{2}{*}{ Total FA } \\
\hline & $\mathrm{C} 14: 0$ & $\mathrm{C} 16: 0$ & C18:0 & cis9-C18:1 & trans11-C18:1 & C18:2 & Other & \\
\hline & & & & & & & & ( $\mu \mathrm{mol}$ per vial) \\
\hline HF-11 & $0 \pm 0^{\mathrm{b}}$ & $39 \pm 3^{\mathrm{a}}$ & $40 \pm 3^{b}$ & $2 \pm 1$ & $0 \pm 0^{\mathrm{a}}$ & $8 \pm 1$ & $11 \pm 1^{b}$ & $5.1 \pm 0.3$ \\
\hline MDT- 10 and HF-11 & $10 \pm 1^{\mathrm{c}}$ & $21 \pm 2^{\mathrm{b}}$ & $4 \pm 1^{\mathrm{a}}$ & $1 \pm 1$ & $51 \pm 4^{\mathrm{b}}$ & $0 \pm 0$ & $13 \pm 2^{b}$ & $5.0 \pm 0.2$ \\
\hline
\end{tabular}

${ }^{\mathrm{a}-\mathrm{c}}$ Means with different superscript letters within a column differ significantly $(P<0.01)$.

${ }^{1}$ Monocultures and cocultures were grown in the presence of $\mathrm{LA}(18 \mu \mathrm{mol} / 30 \mathrm{~mL}$ of medium $)$ for $16 \mathrm{~h}$, and then bacterial cells were washed twice with $0.1 \%(\mathrm{vol} / \mathrm{vol})$ Triton X-100 solution. Mean values of FA $( \pm S E ; n=3)$ in the total lipids are shown.

and 1, 3-DG; 3\%), MG (1-MG and 2-MG; 19\%), and PL (15\%) cell fractions with $t$-VA at molar percentages of $89,78,84$, and $89 \%$, respectively. When HF-11 was grown without $t$-VA, no $t$-VA was detected in either the cells (Table 3 ) or the culture supernatant (data not shown), indicating that HF-11 does not synthesize $t$ VA de novo. The sum of total FA in Table 3 (total FA in cells) was nearly equal between cells grown with $t$ VA $(5.11 \mu \mathrm{mol}$ per vial) and those without $t$-VA (4.94 $\mu$ mol per vial), i.e., the increase in $t$-VA was nearly equivalent to the decreases in other FA, which demonstrates that de novo FA synthesis is suppressed by exogenous $t$-VA.

Diacylglycerol and MG, tentatively identified by TLC (Figure 1), were confirmed by the ratio of FA to glycerol (2:1 and 1:1, respectively) after hydrolysis by lipoprotein lipase. Weak alkali hydrolysis $\left(0.1 \mathrm{~N} \mathrm{NaOH}, 100^{\circ} \mathrm{C}\right.$, $1 \mathrm{~h}$ ) suggested that glycero-PL is the most abundant PL in HF-11 cells (Figure 1). Because these lipids are digested in the small intestine, much of the $t$-VA in HF11 cells may be absorbed by the host animal.

\section{Incorporation of t-VA Produced by Butyr. fibrisolvens MDT-10 into Bifid. adolescentis HF-11 Cells}

Preliminary experiments showed that the specific growth rate of MDT-10 was similar to that of HF-11 (approximately 1.0/h) and that the ratio of concentrations of the 2 bacteria in cocultures, as estimated by microscopy, was unchanged until the stationary phase. These results suggest that there is no antagonism between MDT-10 and HF-11 growth.

When either MDT-10 or HF-11 was grown with LA in monoculture, no $t$-VA was detected in the washed cells (Table 4), demonstrating that MDT-10 does not incorporate $t$-VA and that HF-11 cannot hydrogenate LA to $t$-VA. However, when the 2 bacteria were cultured together in the presence of LA, $t$-VA made up $51 \%$ of total FA in the washed cells, and nearly $80 \%$ of added $\mathrm{LA}(18 \mu \mathrm{mol} / 30 \mathrm{~mL}$ of medium) was recovered as $t$-VA in cells. These results indicate that HF-11 can efficiently incorporate the $t$-VA produced by MDT-10. In the coculture, the percentages of other FA such as 16:0 and 18:0 were decreased, suggesting that de novo FA synthesis in HF-11 was suppressed by exogenously incorporated $t$-VA.

Effect of the Addition of Butyr. fibrisolvens MDT-10 and Bifid. adolescentis HF-11 on t-VA Production and Accumulation in a Batch Culture of Mixed Ruminal Microbes

Addition of MDT-10 (at 1\% of the total number of viable ruminal bacteria) to batch cultures of mixed ruminal microbes $\left(2 \times 10^{11} \mathrm{cfu} / \mathrm{mL}\right)$ greatly enhanced the rate of LA conversion to $t$-VA, leading to concentrations $>4$-fold greater than the control at $3 \mathrm{~h}(P<0.01$; Figure 2 , A and B). However, almost all of the $t$-VA was hydrogenated to SA by $10 \mathrm{~h}$.

However, addition of HF-11 with MDT-10 (at an equal number) decreased the rate of $t$-VA hydrogenation, and $t$-VA accumulation after $10 \mathrm{~h}$ was $>10$-fold greater than in the absence of HF-11 $(P<0.01$; Figure 2 , B and C). When only HF-11 was added, the corresponding value was only 4 -fold greater than the control at $10 \mathrm{~h}(12$ vs. $41 \mu M ; P<0.05)$.

Effect of the Addition of Butyr. fibrisolvens MDT-10 and Bifid. adolescentis HF-11 on t-VA Production and Accumulation in a Continuous Culture of Mixed Ruminal Microbes

The addition of MDT-10 to mixed ruminal microbes grown with LA in continuous culture at a level of $1 \%$ of total viable ruminal bacteria resulted in a $30 \%$ increase in the total amount of $t$-VA flowing from the fermenter in $24 \mathrm{~h}$ (55 vs. $42 \mu \mathrm{mol}, \mathrm{n}=3, P<0.05$; Figure $3, \mathrm{~A}$ and $\mathrm{B})$. The rate of LA conversion to $t$-VA, as well as the concentration of $t$-VA in the effluent, increased with an increasing number of doses of additional LA supplemented at $0,6,12$, and $18 \mathrm{~h}$ (Figure 

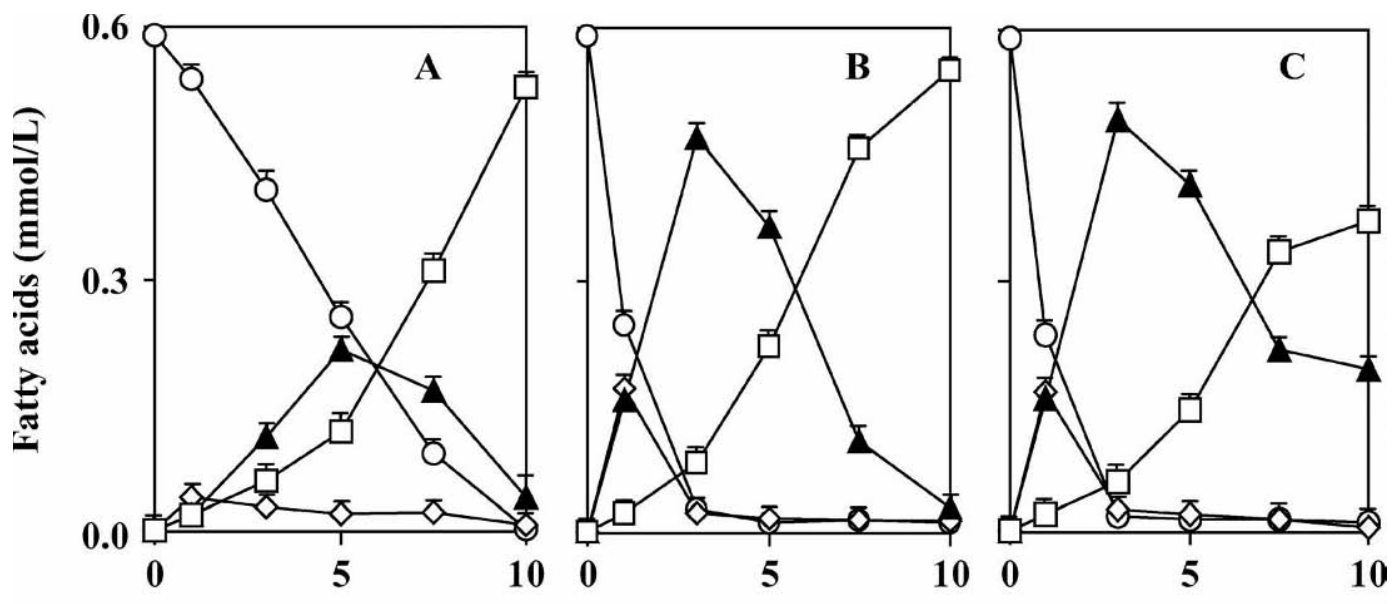

Time (h)

Figure 2. Effect of the addition of Butyrivibrio fibrisolvens MDT-10 and Bifidobacterium adolescentis HF-11 on trans-vaccenic acid ( $t$ VA) production and accumulation in a batch culture of mixed ruminal microbes (total viable bacteria, $2 \times 10^{11} \mathrm{cfu} / \mathrm{mL}$ ). A) Neither of the bacteria was added (control); B) only Butyr. fibrisolvens $\left(2 \times 10^{9} \mathrm{cfu} / \mathrm{mL}\right)$ was added; and C) both Butyr. fibrisolvens $\left(2 \times 10^{9}\right.$ cfu $\left./ \mathrm{mL}\right)$ and Bifid. adolescentis $\left(2 \times 10^{9} \mathrm{cfu} / \mathrm{mL}\right)$ were added. $\bigcirc=$ linoleic acid; $\diamond=$ conjugated linoleic acid; $\boldsymbol{\Delta}=t$-VA; $\square=$ stearic acid. Bars indicate $\mathrm{SE}(\mathrm{n}=3)$

3B). This may be due to an increase in the MDT-10 cell number with time, not due to an increase in LAhydrogenating activity, because the enhancement of LA-I and CLA-R activities by LA attains the maximum within 2 to $3 \mathrm{~h}$ (Fukuda et al., 2005). It is likely that MDT-10 grew at a higher rate than dilution rate (0.1/ $\mathrm{h}$ ). The increase in $t$-VA concentration was greater than that in SA (Figure 3, A and B), suggesting that increased $t$-VA production caused by MDT-10 addition exceeds the capacity of mixed ruminal microbes to hydrogenate $t$-VA. Conjugated LA was not detected in the effluent, probably because the total cell number (or mass) of microbes was $>10^{10} / \mathrm{mL}$ as mentioned previously.

Strain HF-11 added with MDT-10 to a fermenter increased 2 -fold the total amount of $t$-VA in the effluent during $24 \mathrm{~h}$ (108 $\mu \mathrm{mol}, P<0.05$; Figure $3 \mathrm{C})$ compared with a fermenter that received only MDT-10 (55 $\mu \mathrm{mol}$; Figure 3B). The total amount of SA in the effluent greatly decreased (107 vs. $59 \mu \mathrm{mol}, P<0.05$; Figure 3, $\mathrm{B}$ and $\mathrm{C}$ ) despite an increase in $t$-VA production. This suggests that biohydrogenation of $t$-VA was prevented by HF-11 incorporating $t$-VA into its cells and thus preventing the hydrogenation of $t$-VA by other microbes. Similar to the result obtained when MDT-10 was added (Figure 3B), $t$-VA in the effluent increased with an increasing number of additional doses of LA supplemented at 6-h intervals when both MDT-10 and HF-11 were added (Figure 3C). This trend (i.e., $t$-VA in the effluent increased with time) was more pronounced in the presence of both bacteria than with MDT-10 alone. Strain HF-11 may have also grown at a higher rate than the dilution rate $(0.1 / \mathrm{h})$ or $t$-VA-incorporating activity of HF-11 may have increased with time, or both.

Simultaneous addition of MDT-10 and HF-11 increased $t$-VA in the effluent 2.6 -fold during $24 \mathrm{~h}$ relative to a culture that received neither of the bacteria ( $42 \mathrm{vs}$. $108 \mu \mathrm{mol}, P<0.05$; Figure 3, A and C). If MDT-10 and HF-11 are able to keep growing in the rumen, $t$-VA in the ruminal outflow might increase even when these bacteria are added at lower concentrations or less frequently.

In this experiment, continuous culture was performed for only $24 \mathrm{~h}$, because short-term incubation better reflects the microbiota in the rumen. For example, the decline in the number of protozoa, as counted by microscopy, was not large (i.e., explicable by dilution rate). Because protozoa are extremely sensitive to unfavorable environmental conditions (Hino et al., 1993a), most microbes in the rumen might have been maintained. The fermentation products in continuous culture did not significantly change throughout the incubation period (acetate, propionate, butyrate, valerate, and lactate were 35 to 39,17 to 20,15 to 18,2 to 3 , and 4 to $6 \mathrm{mM}$, respectively), suggesting that addition of MDT-10 and HF-11 did not greatly affect the growth of ruminal microbes. Because ruminal contents flow out continuously in ruminants, an increased $t$-VA level in the rumen will result in more $t$-VA flowing out of the rumen as well. Therefore, the addition of both MDT-10 and HF-11 might increase the supply of $t$-VA to the host animal. 

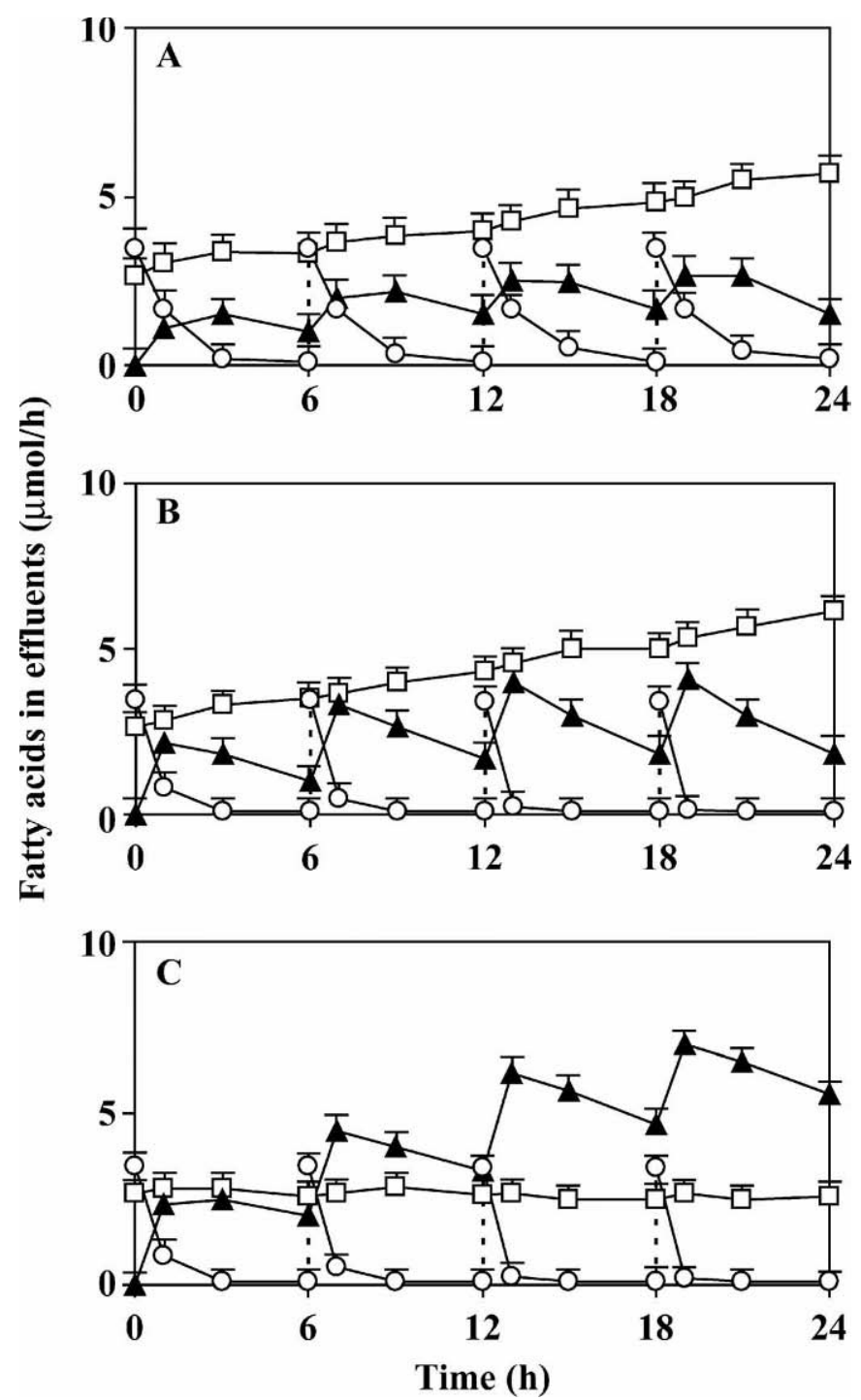

Figure 3. Effect of the addition of Butyrivibrio fibrisolvens MDT10 and Bifdobacterium adolescentis HF-11 on the amount of transvaccenic acid $(t$-VA) in the effluent of continuous culture of mixed ruminal microbes (initial number of total viable bacteria, $1 \times 10^{11}$ $\mathrm{cfu} / \mathrm{mL}$ ). A) Neither of the bacteria was added (control); B) only Butyr. fibrisolvens $\left(1 \times 10^{9} \mathrm{cfu} / \mathrm{mL}\right)$ was added; C) both Butyr. fibrisolvens $\left(1 \times 10^{9} \mathrm{cfu} / \mathrm{mL}\right)$ and Bifid. adolescentis $\left(1 \times 10^{9} \mathrm{cfu} / \mathrm{mL}\right)$ were added. Linoleic acid (LA), carbohydrate, and protein were added every $6 \mathrm{~h}$, and the amounts of LA (O), $t$-VA $(\mathbf{\Delta})$, and stearic acid $(\square)$ in the effluent collected at 1 - $h$ intervals were measured. Values (means \pm $\mathrm{SE} ; \mathrm{n}=3$ ) during 0 to 1,2 to 3 , and 5 to $6 \mathrm{~h}$ after the addition of LA are shown.

\section{CONCLUSIONS}

Addition of Butyr. fibrisolvens MDT-10 to the cultures of mixed ruminal microbes enhanced LA conversion to $t$-VA, and further, the addition of Bifid. adolescentis $\mathrm{HF}-11$ protected $t$-VA against biohydrogenation. Introduction of the 2 bacteria to a continuous culture increased the amount of $t$-VA in the outflow. It is conceiv- able that introduction of the 2 bacteria into the rumen increases $t$-VA flowing out of the rumen, which implies that $t$-VA absorption in the small intestine may be increased; consequently, the conversion of $t$-VA to CLA in tissues may be increased. This may be a beneficial means to increase the CLA content in milk and beef without suppressing overall fermentation in the rumen.

\section{ACKNOWLEDGMENTS}

This study was supported in part by a Grant-in-Aid for Scientific Research (No. 09328, No. 15580240, and No. 16780190) from the Ministry of Education, Culture, Sports, Science, and Technology of Japan; Research Fellowships of the Japan Society for the Promotion of Science for Young Scientists (No. 09328); and "Collaboration with Venture Companies" Project for Private Universities: matching fund subsidy from MEXT (Ministry of Education, Culture, Sports, Science, and Technology), 2001-2005.

\section{REFERENCES}

Bauman, D. E., and J. M. Griinari. 2003. Nutrition regulation of milk fat synthesis. Annu. Rev. Nutr. 23:203-227.

Bryant, M. P. 1986. Genus IV. Butyrivibrio: Section 15. Irregular, nonsporing, gram-positive rods. Pages 1376-1379 in Bergey's Manual of Systematic Bacteriology. Vol. 2. P. H. A. Sneath, N. S. Mair, M. E. Sharpe, and J. G. Holt, ed. Williams \& Wilkins, Baltimore, MD.

Chouinard, P. Y., L. Corneau, W. R. Butler, Y. Chilliard, J. K. Drackley, and D. E. Bauman. 2001. Effect of dietary lipid source on conjugated linoleic acid concentrations in milk fat. J. Dairy Sci. 84:680-690.

Corl, B. A., L. H. Baumgard, D. A. Dwyer, J. M. Griinari, B. S. Phillips, and D. E. Bauman. 2001. The role of delta (9)-desaturase in the production of cis-9, trans-11 CLA. J. Nutr. Biochem. 12:622-630.

Daniel, Z. C., R. J. Wynn, A. M. Salter, and P. J. Buttery. 2004. Differing effects of forage and concentrate diets on the oleic acid and conjugated linoleic acid content of sheep tissues: The role of stearoyl-CoA desaturase. J. Anim. Sci. 82:747-758.

Dhiman, T. R., L. D. Satter, M. W. Pariza, M. P. Galli, K. Albright, and M. X. Tolosa. 2000. Conjugated linoleic acid (CLA) content of milk from cows offered diets rich in linoleic and linolenic acid. J. Dairy Sci. 83:1016-1027.

Dittmer, J. C., and R. L. Lester. 1964. A simple, specific spray for the detection of phospholipids on thin-layer chromatograms. J. Lipid Res. 15:126-127.

Duckett, S. K., J. G. Andrae, and F. N. Owens. 2002. Effect of highoil corn or added corn oil on ruminal biohydrogenation of fatty acids and conjugated linoleic acid formation in beef steers fed finishing diets. J. Anim. Sci. 80:3353-3360.

Fellner, V., F. D. Sauer, and J. K. Kramer. 1997. Effect of nigericin, monensin, and tetronasin on biohydrogenation in continuous flow-through ruminal fermenters. J. Dairy Sci. 80:921-928.

Fukuda, S., H. Furuya, Y. Suzuki, N. Asanuma, and T. Hino. 2005. A new strain of Butyrivibrio fibrisolvens that has high ability to isomerize linoleic acid to conjugated linoleic acid. J. Gen. Appl. Microbiol. 51:105-113.

Fukuda, S., N. Ninomiya, N. Asanuma, and T. Hino. 2002. Production of conjugated linoleic acid by intestinal bacteria in dogs and cats. J. Vet. Med. Sci. 64:987-992.

Griinari, J. M., B. A. Corl, S. H. Lacy, P. Y. Chouinard, K. V. V. Nurmela, and D. E. Bauman. 2000. Conjugated linoleic acid is 
synthesized endogenously in lactating dairy cows by delta-9 desaturase. J. Nutr. 130:2285-2291.

Harfoot, C. G., and G. P. Hazlewood. 1997. Lipid metabolism in the rumen. Pages 382-426 in The Rumen Microbial Ecosystem, 2nd ed. P. N. Hobson and C. S. Stewart, ed. Blackie Academic \& Professional, London, UK.

Hino, T., and N. Asanuma. 2003. Suppression of ruminal methanogenesis by decreasing the substrates available to methanogenic bacteria. Nutr. Abstr. Rev. (Ser. B) 73:1R-8R.

Hino, T., and S. Hamano. 1993. Effects of readily fermentable carbohydrate on fiber digestion by rumen microbes in continuous culture. Anim. Sci. Technol. 64:1070-1078.

Hino, T., M. Sugiyama, and K. Okumura. 1993a. Maintenance of protozoa and methanogens, and fiber digestion in rumen-simulating continuous culture. J. Gen. Appl. Microbiol. 39:35-45.

Hino, T., K. Takeshi, M. Kumazawa, and M. Kanda. 1993b. Effects of aibellin, a novel peptide antibiotic, on rumen fermentation in vitro. J. Dairy Sci. 76:2213-2221.

Hunter, W. J., F. C. Baker, I. S. Rosenfeld, J. B. Keyser, and S. B. Tove. 1976. Biohydrogenation of unsaturated fatty acids. Hydrogenation by cell-free preparations of Butyrivibrio fibrisolvens. J. Biol. Chem. 251:2241-2247.

Jiang, J., L. Bjorck, and R. Fonden. 1998. Production of conjugated linoleic acid by dairy starter cultures. J. Appl. Microbiol. 85:95-102.

Kandler, O., and N. Weiss. 1986. Genus Lactobacillus: Section 14. Regular, nonsporing, gram-positive rods. Pages 1209-1234 in Bergey's Manual of Systematic Bacteriology. Vol. 2. P. H. A. Sneath, N. S. Mair, M. E. Sharpe, and J. G. Holt, ed. Williams \& Wilkins, Baltimore, MD.

Kim, Y. J., R. H. Liu, D. R. Bond, and J. B. Russell. 2000. Effect of linoleic acid concentration on conjugated linoleic acid production by Butyrivibrio fibrisolvens A38. Appl. Environ. Microbiol. 66:5226-5230

Miyazaki, K., T. Hino, and H. Itabashi. 1992. Effects of extracellular $\mathrm{pH}$ on the intracellular $\mathrm{pH}$ and membrane potential of cellulolytic ruminal bacteria, Ruminococcus albus, Ruminococcus flavefaciens, and Fibrobacter succinogenes. J. Gen. Appl. Microbiol. 38:567-573.

Morales, M. S., D. L. Palmquist, and W. P. Weiss. 2000. Effects of fat source and copper on unsaturation of blood and milk triacylglycerol fatty acids in Holstein and Jersey cows. J. Dairy Sci. 83:2105-2111.
Orskov, F. 1986. Genus I. Escherichia: Section 5. Facultatively, anaerobic, gram-negative rods. Pages 420-422 in Bergey's Manual of Systematic Bacteriology. Vol. 2. P. H. A. Sneath, N. S. Mair, M. E. Sharpe, and J. G. Holt, ed. Williams \& Wilkins, Baltimore, MD.

Pariza, M. W. 2004. Perspective on the safety and effectiveness of conjugated linoleic acid. Am. J. Clin. Nutr. 79:1132-1136.

Peterson, D. G., E. A. Matitashvili, and D. E. Bauman. 2004. The inhibitory effect of trans-10, cis-12 CLA on lipid synthesis in bovine mammary epithelial cells involves reduced proteolytic activation of the transcription factor SREBP-1. J. Nutr. 134:25232527.

Piperova, L. S., J. Sampugna, B. B. Teter, K. F. Kalscheur, M. P. Yurawecz, Y. Ku, K. M. Morehouse, and R. A. Erdman. 2002. Duodenal and milk trans octadecenoic acid and conjugated linoleic acid (CLA) isomers indicate that postabsorptive synthesis is the predominant source of cis-9-containing CLA in lactating dairy cows. J. Nutr. 32:1235-1241.

Qiu, X., M. L. Eastridge, K. E. Griswold, and J. L. Firkins. 2004. Effects of substrate, passage rate, and $\mathrm{pH}$ in continuous culture on flow of conjugated linoleic acid and trans C18:1. J. Dairy Sci. 87:3473-3479.

Rajakangas, J., S. Basu, I. Salminen, and M. Mutanen. 2003. Adenoma growth stimulation by the trans-10, cis-12 isomer of conjugated linoleic acid (CLA) is associated with changes in mucosal NF-kappaB and cyclin D1 protein levels in the Min mouse. J. Nutr. 133:1943-1948.

Sauer, F. D., V. Fellner, R. Kinsman, J. K. Kramer, H. A. Jackson, A. J. Lee, and S. Chen. 1998. Methane output and lactation response in Holstein cattle with monensin or unsaturated fat added to the diet. J. Anim. Sci. 76:906-914.

Scardovi, V. 1986. Genus Bifidobacterium. Section 15. Irregular, nonsporing, gram-positive rods. Pages 1418-1434 in Bergey's Manual of Systematic Bacteriology. Vol. 2. P. H. A. Sneath, N. S. Mair, M. E. Sharpe, and J. G. Holt, ed. Williams \& Wilkins, Baltimore, MD.

Spayd, R. W., B. Bruschi, B. A. Burdick, G. M. Dappen, J. N. Eikenberry, T. W. Esders, J. Figueras, C. T. Goodhue, D. D. LaRossa, R. W. Nelson, R. N. Rand, and T. W. Wu. 1978. Multilayer film elements for clinical analysis: Applications to representative chemical determinations. Clin. Chem. 24:1343-350.

Wahle, K. W., S. D. Heys, and D. Rotondo. 2004. Conjugated linoleic acids: Are they beneficial or detrimental to health? Prog. Lipid Res. 43:553-587.

Wang, Y., and P. J. Jones. 2004. Dietary conjugated linoleic acid and body composition. Am. J. Clin. Nutr. 79:1153-1158. 